\title{
Precrack Hysteresis Energy of Elastomer-Modified Polycarbonates in Determining Its Ductile-Brittle Transition
}

\author{
FENG-CHIH CHANG* and HON-CHUN HSU \\ Institute of Applied Chemistry, National Chiao-Tung University, Hsinchu, Taiwan, Republic of China
}

\begin{abstract}
SYNOPSIS
For ductile fracture, the precrack plastic zone has to exceed a critical value, and precrack hysteresis energy has been employed to characterize the plastic zone. The presence of elastomer in polycarbonate is able to enhance precrack hysteresis and, therefore, toughens the polycarbonate matrix. Higher precrack hysteresis means that a greater fraction of the input energy converts into plasticity and leaves less storage energy available to strain the crack tip for crack initiation. If the precrack plastic zone is above the critical value before onset of initiation, the crack growth developed thereafter will be effectively contained within the domain of the plastic zone and results in mass shear, yielding ductile fracture. In this paper, the elastomer toughening is classified as promotion of ductile failure through mass shear yielding and the localized energy dissipation processes. The localized energy dissipations are further divided into the activities occurring on and underneath the fracture surface. A different approach in interpreting the elastomer-toughening mechanism is discussed in detail. (C) 1993 John Wiley \& Sons, Inc.
\end{abstract}

\section{INTRODUCTION}

Polymeric materials show gradual ductile-brittle transition in response to many possible variables that usually can be interpreted with classical or modified fracture mechanics. When the transition is sharp or nearly discontinuous, fracture mechanics is not particularly suitable for such a phenomenon. Polycarbonate with a standard notch exhibits distinct ductile-brittle transition near ambient conditions and therefore has attracted great attention. ${ }^{1-8}$ The mechanism of such a transition is highly complicated and many reasons have been put forward to explain this phenomenon. It is clear that there is no one overriding mechanism responsible for this behavior and an overall review was reported in our previous paper. ${ }^{9}$ We recently discovered the close relationship between the precrack hysteresis and the corresponding ductile-brittle behavior that is applicable to essentially all the variables under investigation for polycarbonate. We proposed a critical precrack plastic volume in determining

* To whom correspondence should be addressed.

Journal of Applied Polymer Science, Vol. 47, 2195-2205 (1993)

(C) 1993 John Wiley \& Sons, Inc.

CCC 0021-8995/93/122195-11 whether the failure is in the ductile or in the brittle mode. ${ }^{10}$ In our previous paper, we used different molecular weights of polycarbonates to demonstrate the existence of a critical precrack plastic volume to differentiate a ductile or a brittle failure.$^{10}$ It is well known that the presence of the soft elastomer is able to toughen the pseudoductile matrices or blends by shifting their ductile-brittle-transition temperatures (DBTT) to lower temperatures. For the elastomer-toughening polycarbonates, the impact strength is decreased when the fracture is in the ductile mode and increased in the brittle mode. ${ }^{9}$ In this paper, we try to utilize the same hysteresis concept to explain the criterion of ductile-brittle transition of the elastomer-toughening polycarbonates. This hysteresis concept can also be extended to determine the critical $J\left(J_{c}\right)$ in the $J$-integral method for elastomer-modified polycarbonate. ${ }^{11,12}$

\section{EXPERIMENTAL}

Natural-grade polycarbonate (PC) with melt flow rate (MFR) of 15 from Dow Chemical Co. was chosen for this study. Core-shell elastomer, EXL 3330, was obtained from Rohm \& Haas. Experimental 
procedures including extrusion blending, injection molding, Izod impact, slow-rate fracture, hysteresis, and scanning electronic microscopy (SEM) were reported previously. ${ }^{9,10}$

\section{RESULTS AND DISCUSSION}

\section{Theoretical Background}

Ward has reviewed the behavior of brittle-ductile transition. ${ }^{13}$ Greater brittle stress $\left(\sigma_{b}\right)$ than the corresponding yield stress $\left(\sigma_{y}\right)$ results in the brittleductile transition, and this simple concept has been repeatedly mentioned in the literature. This simple concept indeed addresses the minimum condition for a ductile failure and may be applicable when the stress field is homogeneous such as in a tensile test. However, in most real situations, especially in a prenotched specimen, the stress field is inhomogeneous and time-dependent. The brittle-ductile transition or plane strain-plane stress transition relates to a characteristic length in a particular test. The transition is characterized by a critical length $x_{\mathrm{oc}}$, where $x_{\mathrm{oc}}=\alpha G_{\mathrm{c}} E / \sigma_{y}^{2}$ and $\alpha$ is a numerical constant whose value is determined by the stress field in the test (for notch bar, $\alpha=0.04$ according Ref. $13)$. The critical length is the plastic zone size at general yield of a notch bar. The fracture transition then occurs at the temperature at which the quantity $\alpha G_{c} E / \sigma_{y}^{2}$ is equal to the critical length in the chosen test. In our previous paper, a critical precrack plastic zone was proposed to differentiate brittle and ductile fractures. ${ }^{10}$ The size of the precrack plastic zone is a function of testing variables, sample conditions, and material modifications that may include deformation rate $(v)$, temperature $(T)$, deformation displacement $(L)$, specimen thickness $(B)$, notch radius $(r)$, matrix yield stress $\left(\sigma_{y}\right)$, molecular weight $(M)$, directionality $(d)$, and elastomer or filler content $(a)$ :

$$
V_{p}=f\left(v, T, L, B, r, \sigma_{y}, M, d, a\right)
$$

Total input energy consists of elastic storage and inelastic hysteresis energy. The contribution of viscoelasticity is considered to be minor under conditions of a very slow deformation rate and can be neglected. The approximate inelastic hysteresis energy can be estimated experimentally from the input energy and the corresponding percent hysteresis loss according to the following equations:

$$
\begin{aligned}
& U_{t}=U_{e}+U_{i}=\int F \cdot L \\
& U_{i}=\Phi \cdot U_{t}
\end{aligned}
$$

where the $U_{t}, U_{e}$, and $U_{i}$ are total input energy, elastic storage energy, and inelastic energy, respectively. $F$ is load and $\Phi$ is percent hysteresis loss. True hysteresis (loss) energy is unobtainable because additional time is necessary to allow for unloading to zero and, therefore, the experimentally obtained hysteresis energy is expected to be higher than the true value. Assume the plastic energy, $U_{p}$, the energy consumed exclusively for plastic-zone formation, has a relationship with the inelastic energy. The precrack plastic volume is also expected to be yield-stress-related:

$$
\begin{aligned}
& U_{p}=K_{1} \cdot U_{i}^{n}=K_{1}\left(\Phi U_{t}\right)^{n} \\
& V_{p}=K_{2} \cdot U_{p} / 6_{y}^{m}=K_{1} \cdot K_{2} \cdot \Phi^{n} \cdot U_{t}^{n} / 6_{y}^{m}
\end{aligned}
$$

where $K_{1}, K_{2}, n$, and $m$ are constants. At the onset of crack initiation, $L=L_{i}$,

$$
\begin{array}{ll}
L_{i}>L_{c} \text { and } V_{p}>V_{c}, & \begin{array}{l}
\text { ductile tearing } \\
\text { ductile or brittle, } \\
\text { or semiductile }
\end{array} \\
L_{i} \cong L_{c} \text { and } V_{p}=V_{c}, & \text { brittle }
\end{array}
$$

\section{Izod Impact}

The impact strengths for the $\frac{1}{8}$ in.-thickness specimens at different temperatures are shown in Figure 1 and are very similar to the results from the methyl methacrylate-butadiene-styrene (MBS)-modified PCs. ${ }^{9}$ The DBTT is decreased with the increase of elastomer content, as would be expected. The presence of only $1 \%$ elastomer is able to reduce the DBTT about $15^{\circ} \mathrm{C}$, as shown in Figure 1 . The elastomer-modified $\mathrm{PC}$ has higher impact strength than does the unmodified counterpart if the failure is in the brittle mode, but has lower impact strength if the failure is in the ductile mode.

A bimodal elastomer-toughening mechanism based on similar observations was proposed previously to interpret such phenomenon. ${ }^{9}$ For the $\frac{1}{4}$ in.thickness specimens, the presence of at least $3 \%$ elastomer is required to shift the DBTT below the ambient temperature (Fig. 2). Figure 3(A)-(D) illustrates the impact fracture surfaces for $\mathrm{PC}+10 \%$ elastomer in both brittle and ductile modes. The 


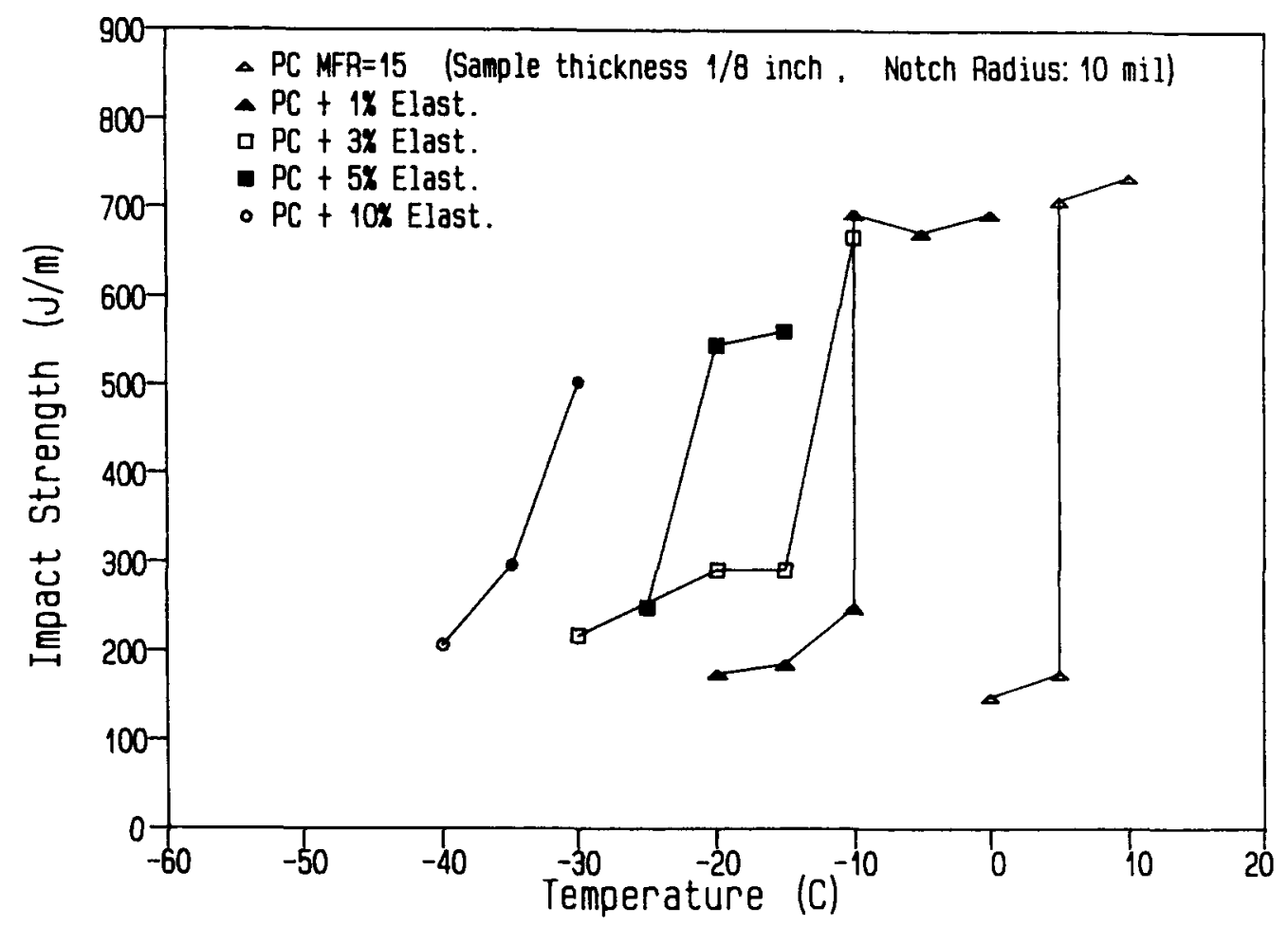

Figure 1 One-eight inch-thickness Izod impact strengths of PCs by varying elastomer contents and temperatures.

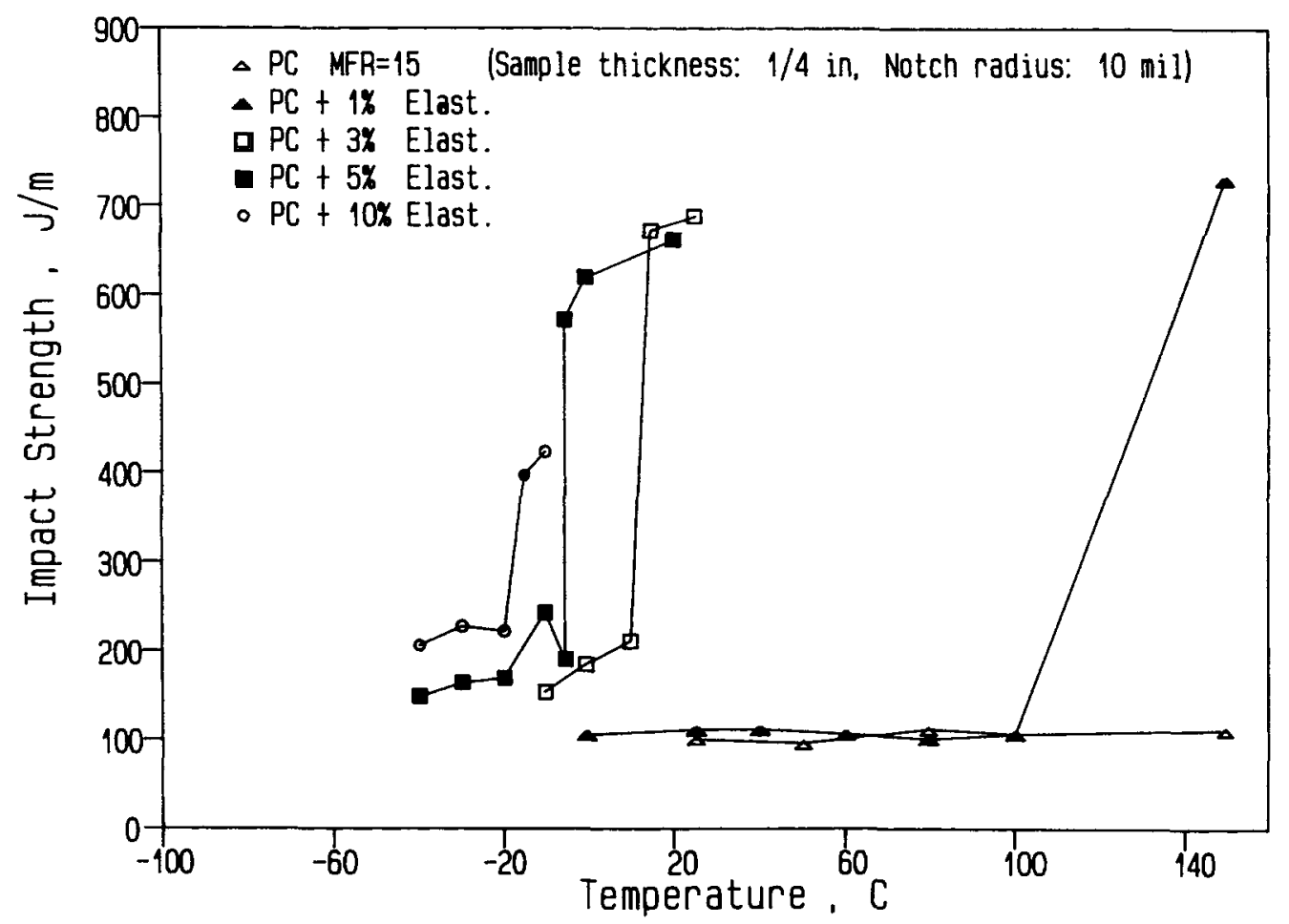

Figure 2 One-fourth inch-thickness Izod impact strengths of PCs by varying elastomer contents and temperatures. 
brittle fracture surface [Fig. 3(A) and (B)] is flat with lots of holes due to rubber debonding from the matrix. The ductile fracture surface [Fig. 3(C) and (D) ] shows extensive mass shear yielding covering the whole fracture surface [Fig. 3(C)] and the elastomer initiated localized shear yielding on the surface [Fig. 3(D)]. The toughness improvement of the elastomer-toughening PCs clearly is shown more by the DBTT shift rather than the minor variation in total fracture energy.

\section{Slow-Rate Fracture}

This is essentially identical to a standard Izod impact test except that the deformation rate of $10 \mathrm{~mm} /$

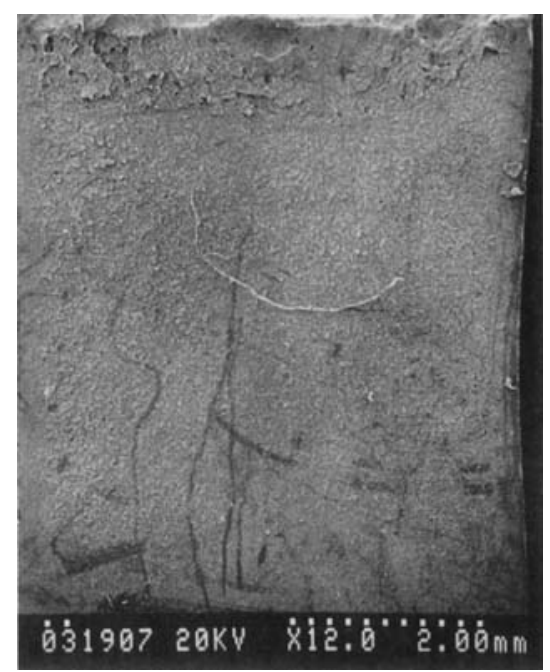

(a)

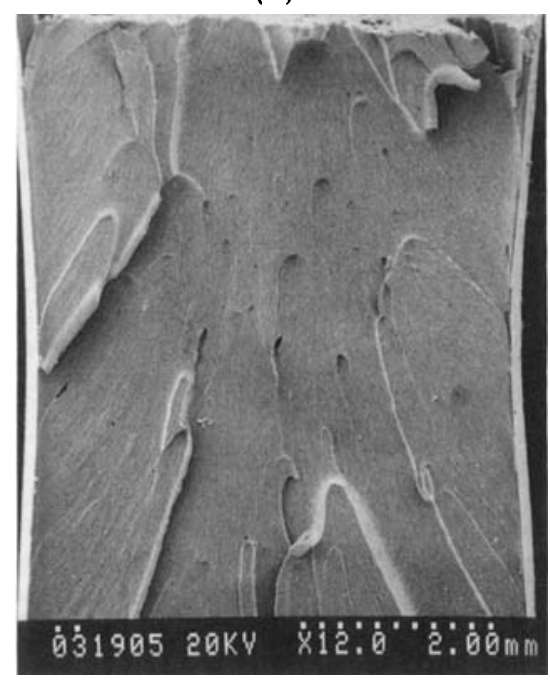

(c) min was employed and controlled by an Instron. Detailed instrument setup and procedures were reported previously. ${ }^{10,14}$ The summarized results from the $\frac{1}{8}$ and $\frac{1}{4}$ in. specimens are shown in Tables I and II. Crack initiation in a plane strain fracture normally occurs prior to the load maximum. ${ }^{10,11,15}$ For convenience and relative comparison, the load maximum is considered as crack initiation in this paper because true initiation for a ductile fracture is difficult to define and to determine. For the $\frac{1}{4}$ in. specimens, the presence of even $1 \%$ of elastomer is able to shift the fracture mode from brittle to ductile (Table II). The unmodified PC is the only one that fractures in the brittle mode, showing significantly lower fracture energy and displacement at breaking

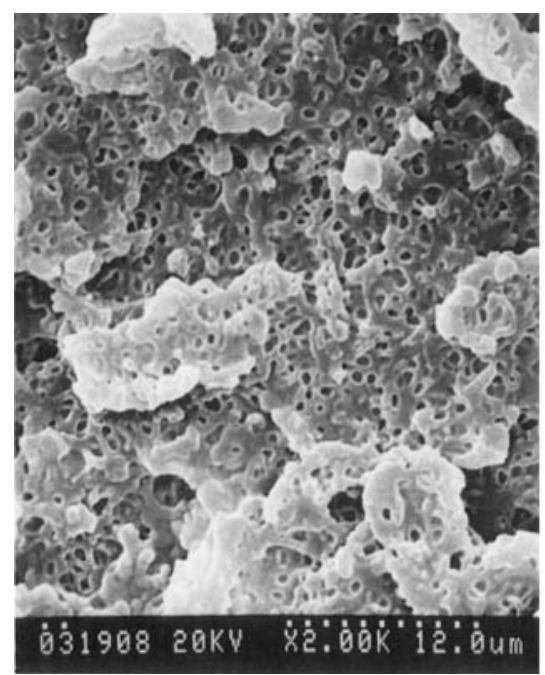

(b)

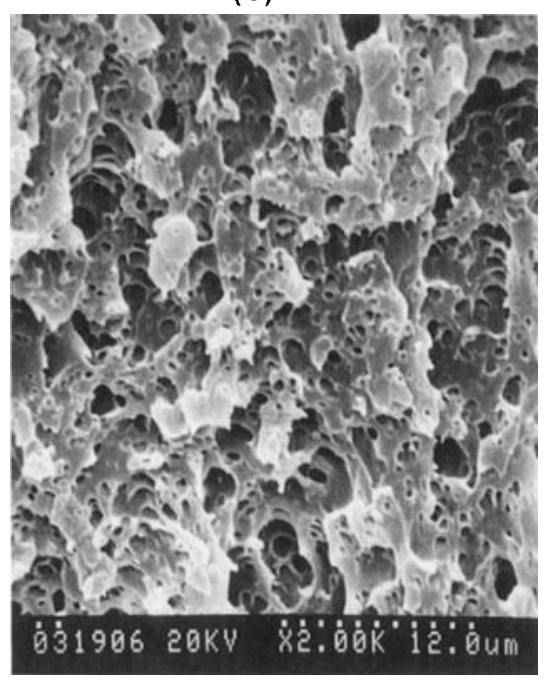

(d)

Figure 3 SEM microphotographs of the brittle and ductile fractured surfaces of PC containing $10 \%$ elastomer: (a) brittle, $\times 12$; (b) brittle, $\times 2000$; (c) ductile, $\times 12$; (d) ductile, $\times 2000$. 
Table I Slow Rate Fracture for $\frac{1}{8}$ in.-Thickness PCs ${ }^{a}$

\begin{tabular}{lccccc}
\hline Sample & $\begin{array}{c}\text { Tangent } \\
\text { Ratio }\end{array}$ & $\begin{array}{c}\text { Total Energy } \\
(\mathbf{J})\end{array}$ & $\begin{array}{c}\text { Energy to Max } \\
\text { Load (J) }\end{array}$ & $\begin{array}{c}\text { Disp. to Max } \\
\text { Load (mm) }\end{array}$ & $\begin{array}{c}\text { Max Load } \\
(\mathrm{KN})\end{array}$ \\
\hline PC15, 0 & 1.000 & 1.95 & 0.65 & 4.16 & 0.230 \\
PC15, 1 & 0.905 & 1.91 & 0.64 & 4.36 & 0.229 \\
PC15, 3 & 0.863 & 1.96 & 0.65 & 4.46 & 0.227 \\
PC15, 5 & 0.824 & 1.86 & 0.68 & 4.51 & 0.222 \\
PC15, 10 & 0.758 & 1.73 & 0.65 & 4.73 & 0.208 \\
\hline
\end{tabular}

a Standard $10 \mathrm{mil}$ notch; deformation rate of $10 \mathrm{~mm} / \mathrm{min}$.

b Tangent of load/displacement at small displacement.

(Table II). PC containing elastomer has less yield stress and modulus, ${ }^{9}$ which is partially responsible for the better resistance to crack initiation. A portion of the precrack input energy is consumed as inelastic, plastic energy and the precrack plastic zone is expected to be increased with the increase of deformation displacement. When the deformation displacement or the crack tip plastic zone exceeds a critical level, the crack developed thereafter will be effectively contained within the domain of the plastic zone and results in a ductile fracture. ${ }^{10}$

The critical deformation displacement of $3.1 \mathrm{~mm}$ for a ductile fracture was obtained previously by varying molecular weights of PCs. ${ }^{10}$ Such critical displacement can be applied in this study for reasons that will be given later. Table II shows that all the elastomer-modified PCs have deformation displacements ( at load maxima) greater than the previously determined critical value of $3.1 \mathrm{~mm},{ }^{10}$ and, therefore, all fractures are in the ductile mode.

Figure 4 (A) - (D) are SEM photomicrographs of the fracture surfaces, which clearly show that the elastomer-initiated surface tearing is shear yielding. It is interesting to note that much more surface tearing shear yielding results from the slow-rate fracture than from the Izod impact [Fig. 4(C) vs. Fig. 3(D)] even though both are ductile fractures. We must cautiously point out here that the observed greater extent of the surface tearing shear yielding does not necessarily represent greater shear yielding or other energy dissipation of the yield region underneath the fracture surface or greater fracture energy. The tearing shear yielding is one of the surface energy dissipation mechanisms that is particularly rate- and temperature-sensitive. In a plane strain brittle fracture of the elastomer-modified polycarbonates under a very slow deformation rate, very similar elastomer-initiated surface tearing shear yielding was previously observed. ${ }^{11}$

We also discovered that greater shear yielding (through elastomer extension ratio) occurred from the brittle fracture than from the ductile fracture underneath the fracture surfaces. ${ }^{9}$ Therefore, surface morphology, used as the sole judgment of material toughness without considering other energy dissipations underneath the surface, can be misleading. However, in a ductile fracture, the mass shear yielding is still the dominant contributor to the total fracture energy, due mainly to its significantly greater yielded total volume rather than its energy dissipation density.

\section{Precrack Hysteresis}

Table III summarizes the results of the hysteresis studies by using four different load levels. Figure 5 shows the plots of precrack hysteresis ratios vs. their corresponding deformation displacements. Hyster-

Table II Slow Rate Fracture for $\frac{1}{4}$ in.-Thickness PCs ${ }^{\mathrm{a}}$

\begin{tabular}{lccccc}
\hline Sample & $\begin{array}{c}\text { Tangent } \\
\text { Ratio }\end{array}$ & $\begin{array}{c}\text { Total Energy } \\
(\mathrm{J})\end{array}$ & $\begin{array}{c}\text { Energy to Max } \\
\text { Load (J) }\end{array}$ & $\begin{array}{c}\text { Disp. to Max } \\
\text { Load (mm) }\end{array}$ & $\begin{array}{c}\text { Max Load } \\
(\mathrm{KN})\end{array}$ \\
\hline PC15, 0 & 1.000 & 0.40 & 0.40 & 2.20 & 0.375 \\
PC15, 1 & 0.846 & 4.36 & 1.50 & 4.76 & 0.483 \\
PC15, 3 & 0.807 & 3.99 & 1.48 & 4.83 & 0.477 \\
PC15, 5 & 0.785 & 3.63 & 1.37 & 5.07 & 0.435 \\
PC15, 10 & 0.705 & 3.41 & 1.25 & 4.91 & 0.422 \\
PC15, 20 & 0.582 & 2.54 & 1.01 & & 0.321 \\
\hline
\end{tabular}


(a)

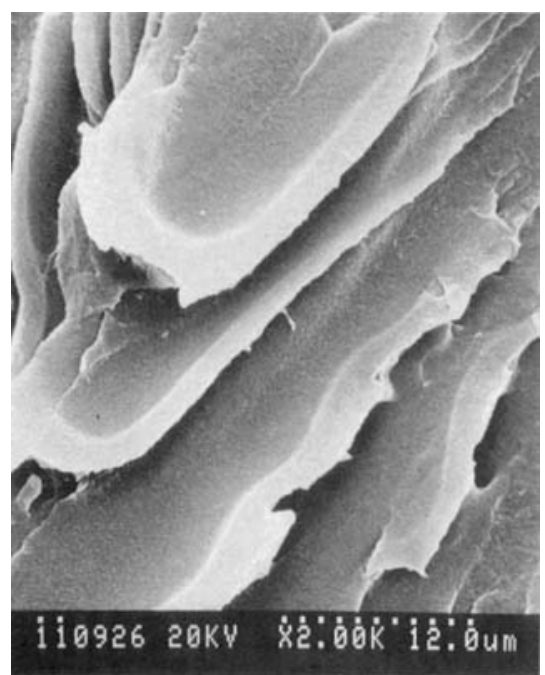

(c)

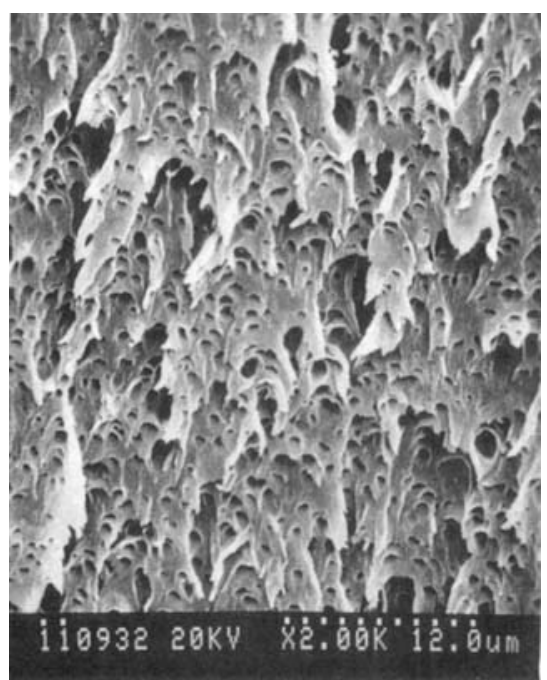

(b)

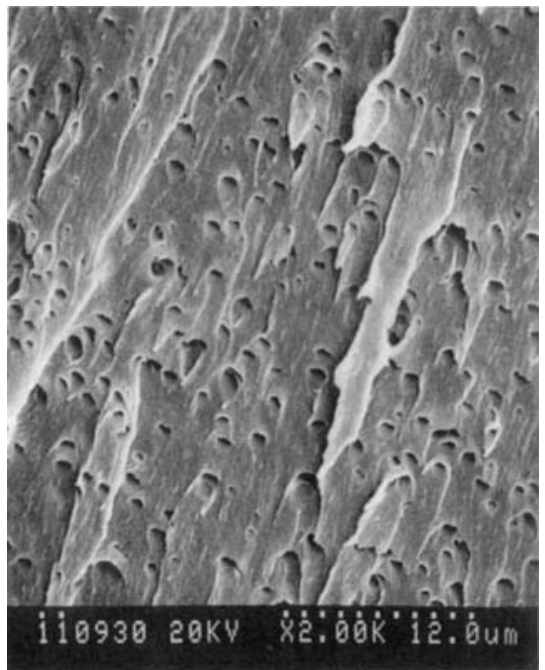

(d)

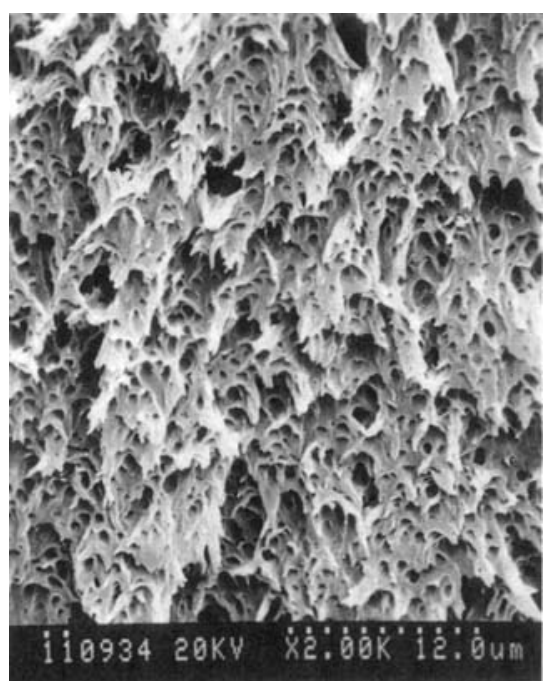

Figure 4 SEM microphotographs of the slow-rate fractured surfaces containing various amount of elastomer at ambient conditions: (a) unmodified PC; (b) 3\% elastomer; (c) $10 \%$ elastomer; (d) $20 \%$ elastomer.

esis ratio increases with the increase of elastomer content, deformation displacement, and load level, as would be expected. When the hysteresis energies instead of the hysteresis ratios are plotted against the deformation displacements, all the data points fall onto a master curve, as shown in Figure 6. For polycarbonate as a matrix, similar results, and nearly identical master curves, were also obtained by varying molecular weights ${ }^{10}$ and temperatures. ${ }^{16}$

Figure 7 clearly demonstrates the effectiveness of elastomer to induce more precrack hysteresis energy. If the observed precrack hysteresis comes strictly from viscoelasticity, the resultant permanent displacement shall be zero. Greater permanent displacement is qualitatively indicative of greater pre- crack plasticity and, thus, of greater precrack plastic zone. The rubbery nature of elastomer particles induces and enhances PC matrix yielding under stress. Figure 8 shows an almost linear relationship between the precrack hysteresis energy and the corresponding permanent displacement for $\mathrm{PCs}$ containing different amounts of elastomer.

\section{Critical Displacement for Ductile-Brittle Transition}

In the previous paper of this series, by varying $P C$ molecular weights, we discovered that PC with MFR $=10$ was exactly at the ductile-brittle transition under the identical experimental conditions used in 
Table III Summarized Hysteresis Data of the Elastomer-Modified PCs

\begin{tabular}{|c|c|c|c|c|c|c|}
\hline $\begin{array}{c}\text { Elastomer } \\
(\%)\end{array}$ & $\begin{array}{l}\text { Load } \\
(\mathrm{KN})\end{array}$ & $\begin{array}{l}\text { Displacement } \\
(\mathrm{mm} \times 10)\end{array}$ & $\begin{array}{c}\text { Permanent } \\
\text { Displacement } \\
(\mathrm{mm} \times 100)\end{array}$ & $\begin{array}{l}\text { Total } E \\
(\mathrm{~J} \times 10)\end{array}$ & $\begin{array}{c}\text { Hysteresis } \\
(\%)\end{array}$ & $\begin{array}{c}\text { Hysteresis } E \\
(J \times 100)\end{array}$ \\
\hline 0 & 0.15 & 7.29 & 1.36 & 0.53 & 3.6 & 0.19 \\
\hline 0 & 0.20 & 9.41 & 2.84 & 0.97 & 6.9 & 0.67 \\
\hline 0 & 0.25 & 12.73 & 9.26 & 1.71 & 15.1 & 2.58 \\
\hline 0 & 0.30 & 16.46 & 12.20 & 2.83 & 16.6 & 4.76 \\
\hline 1 & 0.15 & 7.38 & 3.07 & 0.55 & 6.8 & 0.37 \\
\hline 1 & 0.20 & 9.88 & 6.25 & 1.01 & 12.3 & 1.24 \\
\hline 1 & 0.25 & 13.72 & 10.28 & 1.78 & 16.0 & 2.85 \\
\hline 1 & 0.30 & 17.72 & 15.99 & 2.82 & 17.9 & 5.05 \\
\hline 3 & 0.15 & 7.45 & 3.71 & 0.60 & 7.5 & 0.45 \\
\hline 3 & 0.20 & 10.42 & 7.67 & 1.12 & 13.9 & 1.56 \\
\hline 3 & 0.25 & 13.82 & 12.07 & 1.76 & 17.2 & 3.03 \\
\hline 3 & 0.30 & 17.81 & 16.19 & 3.01 & 20.2 & 6.08 \\
\hline 5 & 0.15 & 7.91 & 4.05 & 0.61 & 8.9 & 0.54 \\
\hline 5 & 0.20 & 10.95 & 9.37 & 1.13 & 15.1 & 1.71 \\
\hline 5 & 0.25 & 14.01 & 13.17 & 1.90 & 18.4 & 3.50 \\
\hline 5 & 0.30 & 20.45 & 20.69 & 3.43 & 22.3 & 7.65 \\
\hline 10 & 0.15 & 8.64 & 5.13 & 0.65 & 11.3 & 0.73 \\
\hline 10 & 0.20 & 12.47 & 9.64 & 1.32 & 16.3 & 2.15 \\
\hline 10 & 0.25 & 14.55 & 15.12 & 1.97 & 20.0 & 3.94 \\
\hline 10 & 0.30 & 22.01 & 28.03 & 3.77 & 24.6 & 9.27 \\
\hline 20 & 0.15 & 9.86 & 7.86 & 0.76 & 17.0 & 1.29 \\
\hline 20 & 0.20 & 16.00 & 18.70 & 1.73 & 23.9 & 4.13 \\
\hline 20 & 0.25 & 22.00 & 34.92 & 3.22 & 32.1 & 10.34 \\
\hline 20 & 0.30 & 32.59 & 64.45 & 5.97 & 39.4 & 23.52 \\
\hline
\end{tabular}

this study-some fractured in the ductile mode and some in the brittle mode. ${ }^{10}$ The critical deformation displacement of $\mathrm{PC}$ was thus determined from the PC $(M F R=10)$. In the present study, all the elastomer-modified $\mathrm{PCs}$, even as low as $1 \%$, result in ductile fracture and the determination of critical displacement based on elastomer contents becomes impossible. However, due to the nearly identical master curves from the plots of displacement vs. hysteresis energy derived by changing PC molecular weights, elastomer contents, and temperatures, we believe that the critical displacement obtained from molecular weight changes is applicable to the other two systems.

\section{Elastomer-Toughening Mechanism}

Since the development of high-impact polystyrene, the elastomer-toughening mechanism has been the subject of extensive investigations in terms of macroscopic or microscopic views. Macroscopically, we will classify the elastomer-toughening pseudoductile matrices phenomenologically into two major parts: promotion of brittle-to-ductile failure through mass shear yielding and elastomer-initiated localized en- ergy dissipations. These two closely related processes occur and overlap in any fracture: The former is dominant in a ductile fracture and the latter is dominant in a brittle failure.

Full mass shear yielding usually occurs only on relatively thin (plane stress) specimens ( 0.25 in. or less). Here we define the ductile fracture with full mass shear yielding as that where the whole fracture surface is covered with mass shear yielding and clear lateral contraction. Because of greater degrees of plane strain, full mass shear yielding for thicker specimens (greater than $0.25 \mathrm{in}$.) becomes difficult to achieve. In such a situation, semiductile fracture may occur with mass shear yielding on both sides of the specimen and plane strain flat surface in the center. ${ }^{17}$ Elastomer toughening not only enhances mass shear yielding but also enhances those abovementioned localized energy dissipations. The presence of elastomer can effectively resist the crack initiation by allowing a greater extent of precrack plasticity, which also helps localized energy dissipations during later crack propagation. This is shown by the slightly more surface tearing shear yielding observed from the ductile fracture [Fig. 3(D)] than from the brittle fracture [Fig. 3(B)]. 


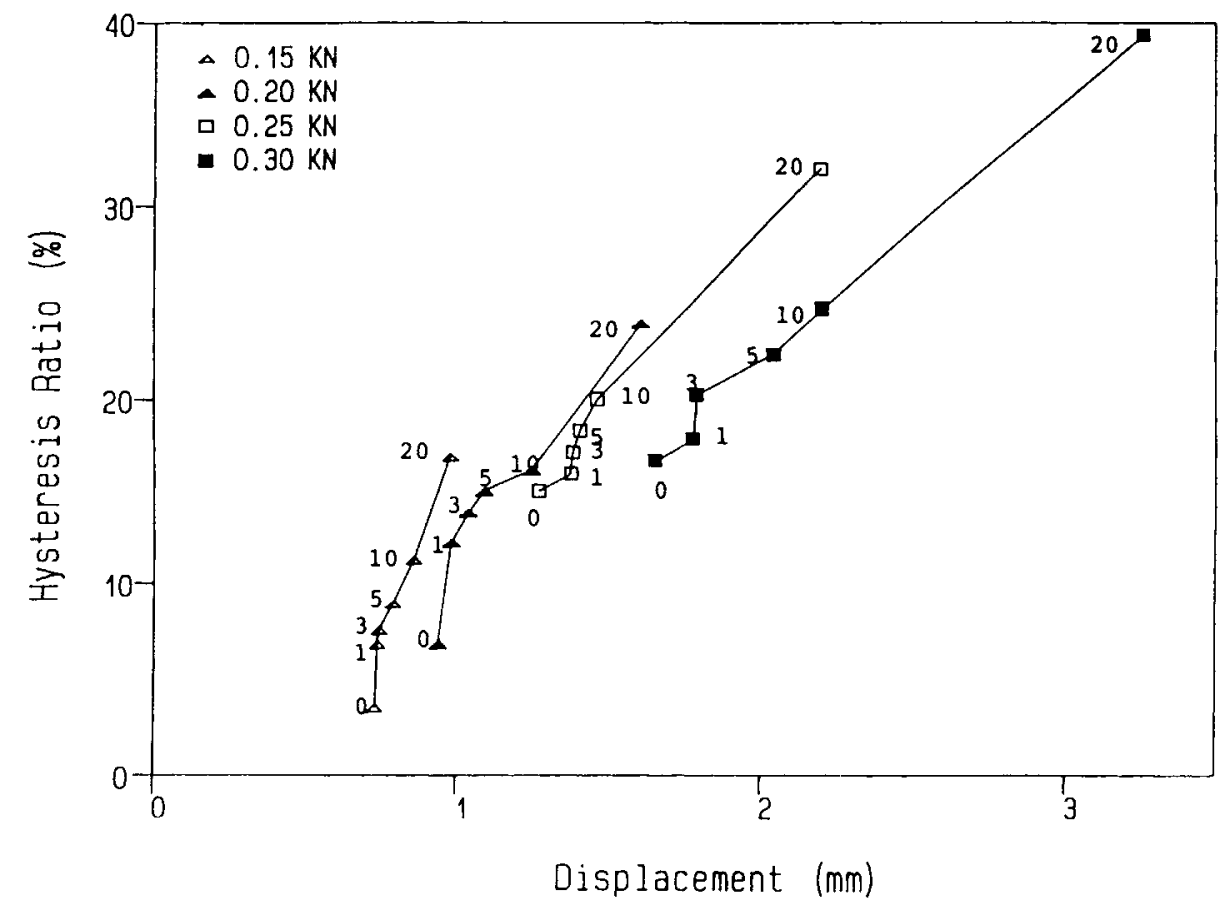

Figure 5 Plots of deformation displacement vs. percent hysteresis ratio for PCs containing various elastomer contents under four different loads.

A slower deformation rate is also an important factor to promote both mechanisms. A reduced deformation rate switches the fracture mode from brittle to ductile (for PC $+10 \%$ elastomer) and in- creases the surface tearing shear yielding [ Fig. 4(C) vs. Fig. 3(D) ]. The promotion of ductile fracture emphasizes the resistance to crack initiation, although the occurrence of mass shear yielding takes

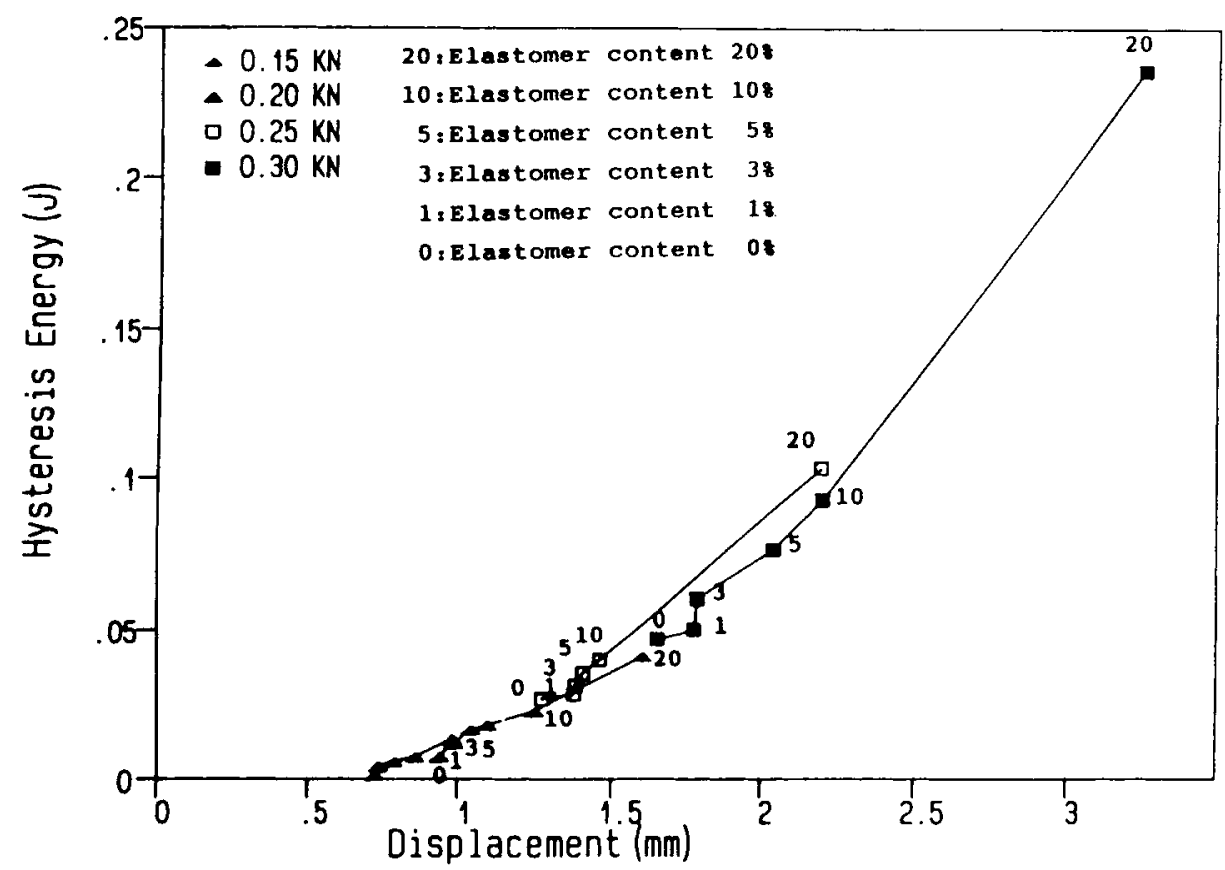

Figure 6 Plots of deformation displacement vs. hysteresis energy for PCs containing various elastomer contents. 


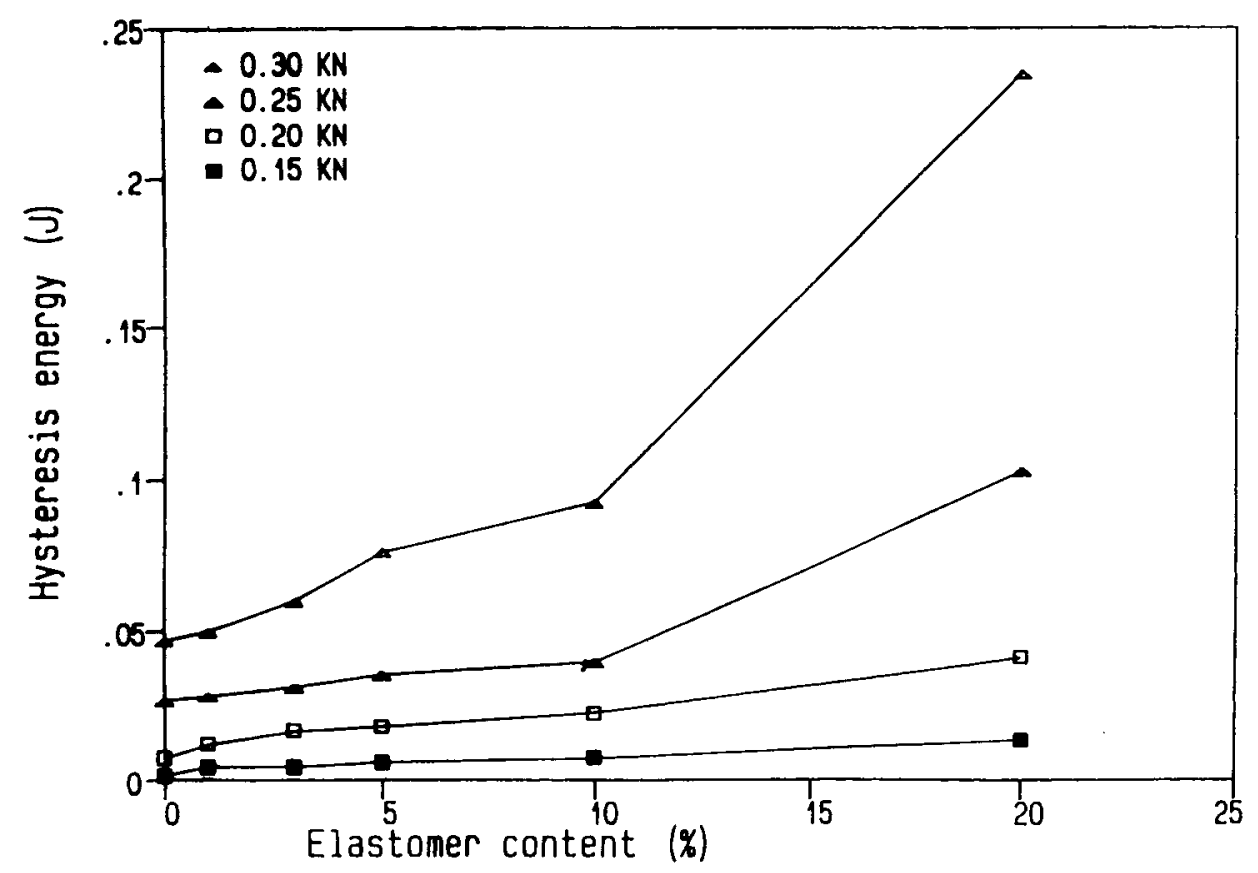

Figure 7 Effect of elastomer content on precrack hysteresis energy.

place both before and after crack initiation. The elastomer-promoted mass shear yielding does not necessarily result in higher fracture energy or greater mass shear yielding volume. As mentioned previously, the elastomer-modified polycarbonates ac- tually result in less fracture energy than does the unmodified counterpart when the fracture is in the ductile mode. ${ }^{9}$

Other pseudoductile matrices, such as the elastomer-modified nylon and polyacetal, have higher

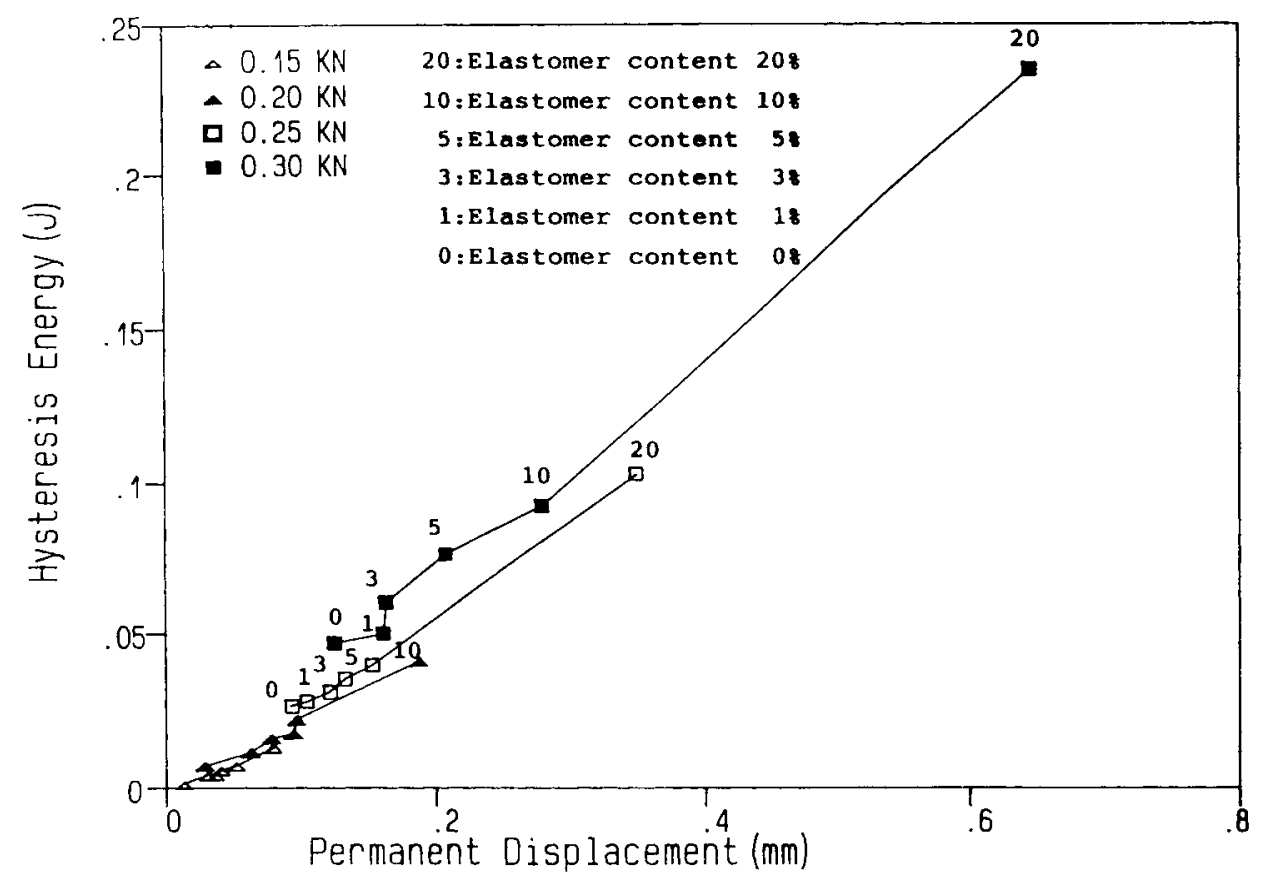

Figure 8 Relation of precrack hysteresis energy and resultant permanent displacement for PCs containing various amount of elastomer contents. 


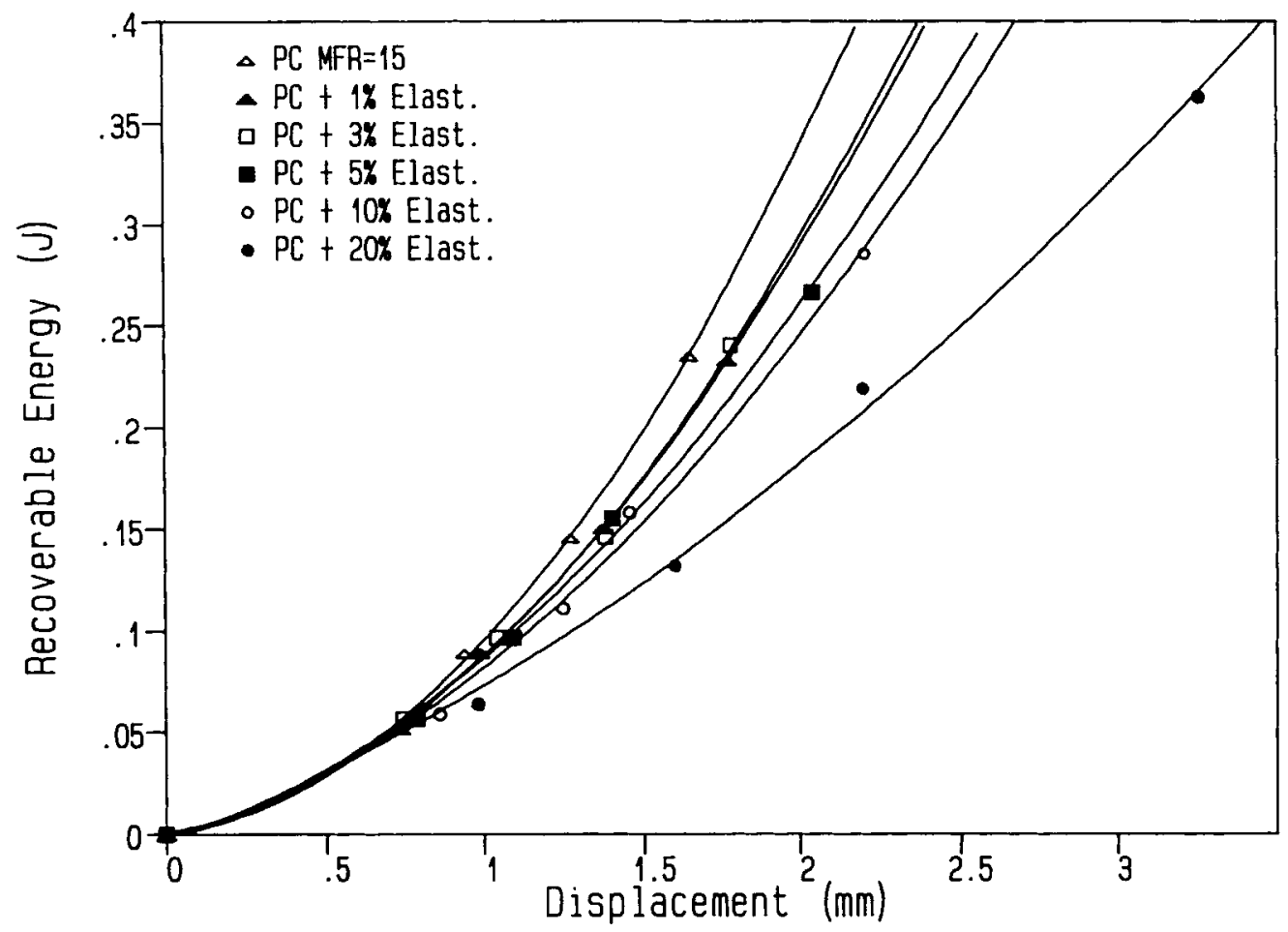

Figure 9 Plots of deformation displacement vs. precrack recoverable energy for PCs containing various elastomer contents.

fracture energies than do their corresponding unmodified matrices. ${ }^{14,18}$ The elastomer-initiated localized energy dissipations may include activities occurring on the surface ( such as surface free energy, elastomer cavitation, elastomer debonding, and matrix tearing shear yielding) and underneath the surface (such as localized shear yielding, crazing, elastomer cavitations, and elastomer matrix debonding) .

Again, these two types of energy dissipation are closely related and can influence each other. Unmodified polycarbonate shows an insignificant extent of surface energy dissipation in either ductile or brittle fracture. ${ }^{9}$ In the elastomer-modified polycarbonates, it is undoubtedly clear that the importance of the surface tearing shear yielding increases with the increase of elastomer content, although the fraction made up of the total localized energy dissipations (on and below the surface) is difficult to determine. The total yielding volume of these localized energy dissipations, on the surface and in the vicinity under the fracture surface, is considered to be significantly less than the mass shear yielding. At lower temperature (but still above $T_{g}$ of the elastomer) and higher elastomer contents, the sum of these elastomer-induced localized energy dissipations becomes the major contributor of the total fracture energy in the brittle fracture. That is why the elastomer-modified polycarbonate has significantly higher fracture energy than does the unmodified polycarbonate in low-temperature brittle failure. ${ }^{9}$

In the earlier theoretical background section, we have already pointed out that the deformation displacement or the precrack plastic zone had to exceed a critical level for ductile fracture. The important question is how to prove that the presence of the elastomer in a matrix is indeed able to resist and delay the crack initiation and let the precrack plastic zone exceed the critical value. In this paper, we have repeatedly emphasized that the presence of more elastomer results in a greater portion of the input energy converting into precrack plastic zone. The reasons for a crack to propagate are highly complex and numerous factors have to be considered. The plane strain fracture mechanics approach is relatively simple because the precrack plasticity is essentially neglected and the input work is considered exclusively for crack initiation. The storage or recoverable energy, the input energy minus the hysteresis energy, is undoubtedly considered the major driving force for crack initiation. The presence of elastomer diverts part of the input energy into inelastic hysteresis and reduces the strain on the ex- 
isting crack tip and therefore delays the onset of crack initiation. Figure 9 demonstrates the effectiveness of the elastomer in reducing the recoverable energy available for crack initiation.

This paper does not look into the elastomertoughening mechanism in a very detailed microscopic way. Based on microscopy, Yee and co-workers observed and proposed the mechanism the cavitation of rubber particles first and then subsequent shear yielding. ${ }^{19}$ Probably due to the use of different elastomers from different manufacturers, we did not observe similar elastomer cavitation even though the elastomer particles were elongated to at least $500 \% .^{9}$ Therefore, we suspect that the rubber cavitation is really a necessary step in order to complete the rubber-toughening mechanism even though the rubber cavitation may happen. In other words, elastomer cavitation is not an important or necessary step in the elastomer toughening of polycarbonate. We feel that the soft nature of the elastomer particles (above $T_{g}$ ) alone is able to relieve the triaxial tension and therefore enhances shear yielding of the surrounding matrix. Because of the elastic nature of the elastomer particles, their presence is not expected to contribute to the observed hysteresis energy to any substantial extent in this study and that is why a master curve based on plots of hysteresis vs. displacement can be obtained.

\section{CONCLUSIONS}

Elastomer-induced precrack energy dissipations enhance plasticity and reduce the storage energy available to strain the crack tip for crack initiation. The presence of the elastomer, in turn, will retard the onset of crack initiation and therefore allows the precrack plastic zone to exceed the critical value prior to crack initiation. As soon as the precrack plastic zone is greater than the critical value, the crack developed thereafter will propagate within the domain of the plastic zone and results in a ductile fracture. Phenomenologically, we classify the elastomer-toughening mechanism into the promotion of ductile failure by mass shear yielding and localized energy dissipations, although both are closely related. Elastomer promotes both mechanisms, with the former dominating in the ductile failure and the latter dominating in the brittle failure. In the localized energy dissipations, we also divide them into activities occurring on the surface and beneath the surface. Greater surface tearing shear yielding does not necessarily mean greater energy dissipation underneath the surface or greater overall toughness. Unfortunately, this has been the assumption of most of the literature. A direct relationship between the precrack hysteresis found and corresponding ductility in PC has been observed in essentially all the variables tested and we will report later on these observations.

The authors are grateful to the National Science Council of Republic of China for financial support.

\section{REFERENCES}

1. D. G. Legrand, J. Appl. Polym. Sci., 13, 2129 (1969).

2. G. Allen, D. C. W. Morley, and T. Williams, J. Mater. Sci., 8, 1449 ( 1973).

3. N. J. Mills, J. Mater. Sci., 11, 363 (1976).

4. T. J. Ryan, Polym. Eng. Sci., 18, 264 (1978).

5. A. F. Yee, J. Mater. Sci., 12, 757 (1977).

6. G. L. Pitmam, I. M. Ward, and R. A. Duckett, J. Mater. Sci., 13, 2092 (1978).

7. L. E. Hornberger, G. Fan, and K. L. DeVries, J. Appl. Phys., 60, 2678 (1986).

8. C. K. Riew and R. W. Smith, in Rubber-toughened Plastics, C. K. Riew, Ed., Advances in Chemistry 222, American Chemical Society, Washington, DC, 1989, p. 225.

9. F. C. Chang, J. S. Wu, and L. H. Chu, J. Appl. Polym. Sci., 44, 491 (1992).

10. F. C. Chang and H. C. Hsu, J. Appl. Polym. Sci., 43, 1025 (1991).

11. C. B. Lee and F. C. Chang, Polym. Eng. Sci., 32, 792 (1992).

12. C. B. Lee, M. L. Lu, and F. C. Chang, J. Chin. I.Ch.E., 23, 305 (1992).

13. I. M. Ward, Mechanical Properties of Solid Polymers, 2nd ed., Wiley, Chichester, UK, 1983, pp. 432-436.

14. F. C. Chang and M. Y. Yang, Polym. Eng. Sci., 30, $543(1990)$.

15. I. Narisawa and M. T. Takemori, Polym. Eng. Sci., 28, 1463 (1988).

16. H. C. Hsu and F. C. Chang, in Proceedings of the Annual Conference of the Chinese Society for Materials Science, Taiwan, 1990, p. 1005.

17. W. B. Liu and F. C. Chang, to appear.

18. S. Wu, Polymer, 26, 82 (1985).

19. D. S. Parker, H. J. Sue, and A. F. Yee, Polymer, 31, 2267 (1991).

Received January 9, 1992

Accepted May 12, 1992 